\title{
Differences in the perception of a mass media information campaign on drug and alcohol consumption
}

\author{
by \\ Godin $\mathrm{I}^{1}$, Dujardin $\mathrm{S}^{1}$, Fraeyman $\mathrm{J}^{2}$, Van Hal $\mathrm{G}^{2}$
}

\begin{abstract}
The two-month mass media campaign in Belgium on drug and alcohol consumption "Alcohol and other drugs. The facts and fictions" initiated in January 2008 has been evaluated shortly after by a phone survey. This article reports some indicators on the public awareness of the campaign, and the differences in the perception according to age groups and education levels.
\end{abstract}

About 1,000 respondents $(n=1,002)$ accepted to participate in the campaign evaluation. Response rate is $37.1 \%$. Global perception of the campaign - measured by the capacity to identify the campaign adequately - is $18.8 \%$. This perception varies between age groups and education levels: $30 \%$ of the youngest age group (14-35 yrs) have seen the campaign, $13 \%$ of people aged 56 and over $(p<0.001)$. The lower the education level, the lower the probability to have seen the campaign (11\% in the lowest group, $25 \%$ in the highest one, $p<0.001)$.

Among the respondents who have seen the campaign, newspapers are the most often cited media for the oldest age groups. Inversely, young people have mainly identified the campaign on street boards or on post cards.

The privileged type of media is also function of the education level. People belonging to the lowest educational level report more often to have seen the campaign on TV (85\% vs $51 \%$ in the highest group, $p<0.01)$, while the reverse is true for seeing the campaign via the newspapers or the street boards.

The results indicate that there are socio-economic variations in the perception of the campaign. In health promotion, reaching lower socio-economic groups still remains a real challenge. Channels for such campaigns have to be carefully chosen to reach their target groups and ask to be complemented with community based interventions.

\section{Introduction}

A two-month Belgian information campaign was launched in January 2008 by iDA (a Belgian non-profit organization on information on Drugs and Alcohol). This campaign was initiated through mass media, and called: "Alcohol and other drugs. The facts and fictions".

\footnotetext{
1 School of Public Health Université Libre de Bruxelles

2: Medische sociologie en gezondheidsbeleid Universiteit Antwerp igodin@ulb.ac.be
} 
This campaign aimed to initiate reflection and discussion about drug and alcohol consumption in the general population first, but young people and their parents in particular. Open communication between teens and their parents seems to be an effective preventive factor regarding substance abuse (1). Besides this objective, the campaign wanted to provide information on support organizations (their website and phone contact).

The campaign used different media, i.e. 235,000 postcards distributed in places frequented by young people (bars, dance halls, schools...), 531 large posters $\left(20 \mathrm{~m}^{2}\right)$ in public areas, 60 advertisements in newspapers, 255 television spots and online information on the website of iDA. All campaign supports exist in French and Dutch.

The messages were conceived like a quiz game or rumor demystification operation, with a question related to drug or alcohol consumption coming first (true or false statement), followed by the correct answer ${ }^{1}$. An invitation to contact a reference center on drug information, including a website address and a phone number were available on all supporting media.

Besides the aim to reach the general population, specific material (booklet, board game...) was also elaborated for professionals working in the addiction sector or with young people.

The aim of this article is to document the impact of this campaign, aimed to reach the general population, and to see if the campaign equally reached the different social groups. This impact evaluation was made by an interuniversity staff (one Dutch- and one French-speaking university) during three months (March until May 2008).

\section{Materials and methods}

Immediately after the campaign ended, in March 2008, a telephone survey was conducted in order to collect information on the public awareness as well as opinions and comments of the general Belgian public on the campaign.

The telephone survey was the selected method in order to cover the whole country. Compared to postal surveys, telephone surveys generate higher response rates (2). The main purpose of the survey was to collect the opinions of a great sample of respondents in a large geographic area and in a short period of time in order to avoid recall bias. Therefore, a telephone survey represents a fast, reliable and cheap method to collect such data. Contact with an interviewer, even by phone, could eventually generate a phenomenon of social desirability. This could be observed while gathering information on behavior, but seems not to be the case for opinions (3). For those reasons, a telephone survey seemed to be the most appropriate method.

A proportionate allocation of an initial list of 10,000 phone numbers was performed in order to respect the language repartition and to account fore the geographical spread over the 10

\footnotetext{
1 More information on iDA website: http://www.infordrogues.be/ida/vrai-ou-faux.html or http://www.druglijn.be/feiten fabels/over-de-campagne.html
} 
provinces of the country. The Dutch-speaking community consisted of $60 \%$ of the respondents and the French-speaking community of $40 \%$.

Phone contacts were conducted during and outside working hours, during weekdays and during weekends. We included respondents of 14 years and older. Since it is known that younger people use mobile phones more - which were not included in our list of fixed phone lines -, we also performed street interviews in Antwerp and Brussels to get enough reliable information on this age group.

The questionnaire included items concerning the campaign: having seen the campaign or not; if yes: where (which medium), the global appreciation of the campaign (measured by a 10 points satisfaction scale, 1 indicating a very bad appreciation and 10 an excellent appreciation), the possible discussion and reflection that could be induced by the campaign, and some socio-economic characteristics of the respondent (sex, age, education level, profession). In this paper, differences between some key variables of the campaign and education level and age will be presented.

For the purpose of the analysis, respondents were categorized in three age groups: teenagers and young adults (14-35 yrs), middle-aged adults (36-55 yrs) and seniors (56 and over). Education level was recoded in four groups: first degree of secondary school, vocational secondary school (second degree), secondary school (second degree) and college/university degree.

Differences between proportions were calculated with Pearson chi square, at $5 \%$ significance level. Mean score differences (global satisfaction score) were compared between categorical variables using one-way analysis of variance (Anova), at the same level of significance.

\section{Results}

Of all persons who were phoned, a total of 1,002 interviews were conducted (response rate $37.1 \%)$. Table 1 describes the socio-economic characteristics of the respondents.

About $19 \%$ of the respondents have seen the campaign $(18.8 \%)$. There are no significant differences between Dutch- and French-speaking respondents. Important differences are, however, observed between age groups and education levels: $30 \%$ of the youngest age group (14-35 yrs) has seen the campaign vs. $13 \%$ of the seniors $(p<0.001)$. The lower the education level, the lower the probability to have seen the campaign $(11 \%$ in the lowest group, $25 \%$ in the highest one, $p<0.001$ ).

Because less people aged 56 and over belong to the highest educational group compared to the young generation, we have stratified the association between the variable "have seen the campaign" and education level by age groups. This stratified analysis does not show statistically significant associations between education and "have seen the campaign" in the young age groups. But a statistically significant association is observed between those two variables in the oldest age group. 
Table 1: Sample description

\begin{tabular}{llll}
\hline Age in years $(\mathrm{n}=996)$ & $\mathrm{N}$ & $\%$ & Mean (std dev.) \\
\hline $14-35$ & 237 & 23.8 & 52.28 yrs (19.76) \\
$36-55$ & 260 & 26.1 & \\
56 and + & 499 & 50.1 & \\
\hline Sex $(\mathrm{n}=998)$ & & & \\
\hline man & 341 & 34.2 & \\
woman & 657 & 65.8 & \\
\hline Education level (n=957) & & & \\
\hline first degree of secondary school & 229 & 23.9 \\
vocational secondary school (second degree) & 155 & 16.2 & \\
secondary school (second degree) & 241 & 25.2 \\
college/university degree & 332 & 34.7 & \\
\hline
\end{tabular}

When we consider only the respondents who have seen the campaign $(n=188)$, we notice important differences between generations on the type of media. More than one third of the people aged 36-55 have read the campaign in newspapers (35.3\%): this is the highest percentage among the three age groups; $21.5 \%$ of the seniors (56 and over) and only $14.1 \%$ of the youngest age group $(p<0.05)$. Inversely, young people have seen the campaign on street boards more often $(32 \%$, vs. $15 \%$ in the oldest aged group and $19.6 \%$ in the middle aged group, $p=0.05)$. The postcards have been exclusively seen by young people $(14.1 \%)$.

Figure 1: Media through which the campaign was seen, by age group (in $\%, n=188$ )

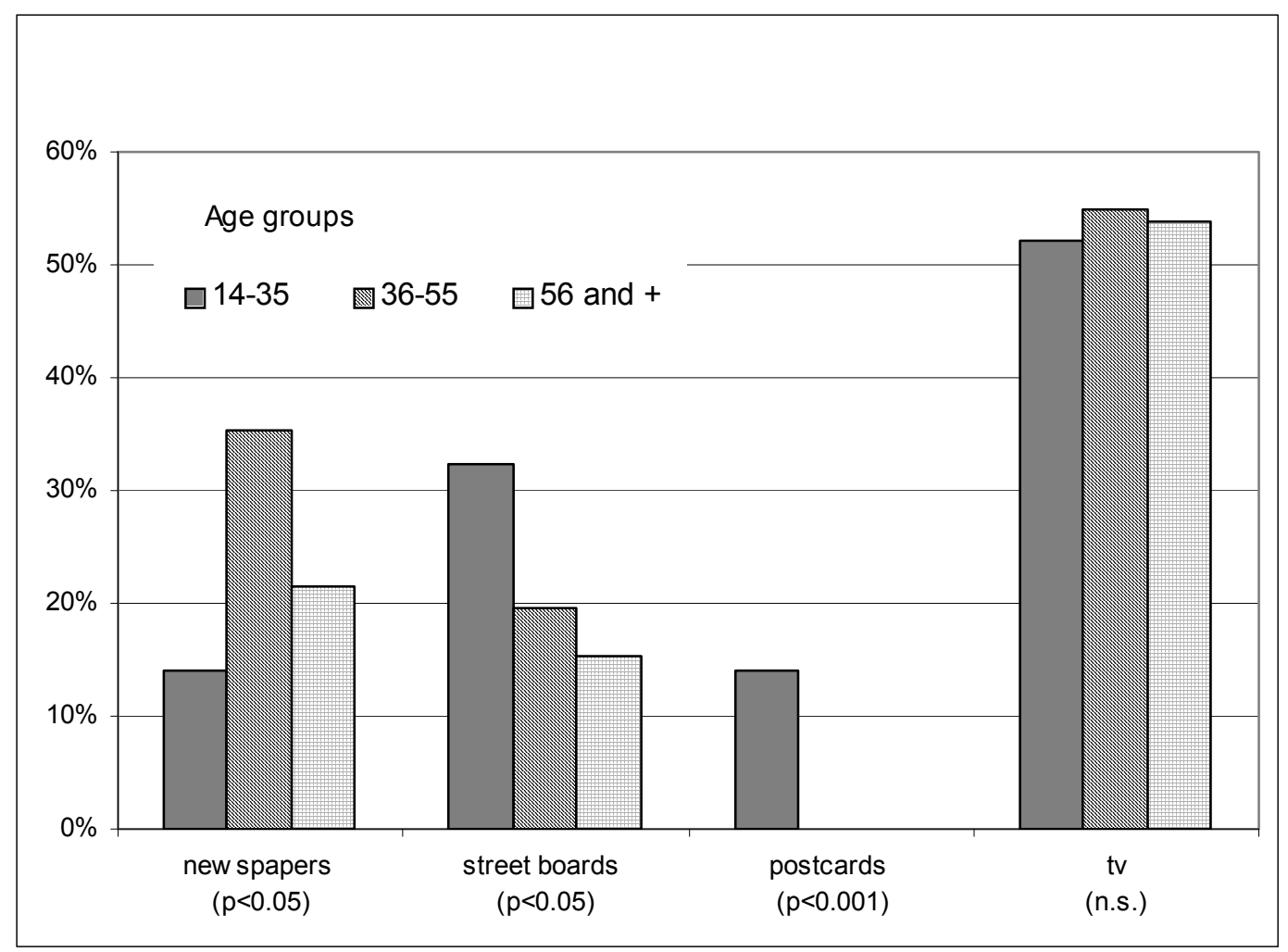


The privileged type of media is also function of the education level. People belonging to the lowest educational level report more often to have seen the campaign on TV (85\% vs. 51\% in the highest group, $p<0.01$ ), while the reverse is true for having seen the campaign in the newspapers $(23 \%$ in the highest educational group, $8 \%$ in the lowest, but this difference does not reach the $5 \%$ level of signification) or the street boards ( $30 \%$ vs. $8 \%$ respectively, $p<0.05$ ) (Figure 1).

Items measuring the appreciation of the campaign, (such as "this campaign is eye-catching", "I feel personally concerned with the campaign", "this campaign is well done") do not vary according to the education level, neither to age.

After having been in contact with the campaign, people aged 56 and over report more often to have discussed about their own consumption with friends/acquaintances than younger age groups ( $52 \%$ vs. $32 \%$ of the $14-35$ yrs old respectively, $p<0.05)$.

Global satisfaction of the campaign was measured with a scale varying between 1 ("very poor quality") and 10 ("very high quality"). The mean score increases with age: 6.17 in the first age group, 6.80 in the 36-55 yrs one and 7.05 in the age group 56 yrs and over, $\mathrm{p}=0.089$ ). There are no statistically significant score differences across education levels.

Finally, among the respondents who saw the campaign, only 37 out of the $188(20 \%)$ were able to provide the name of the support organization that launched the campaign.

\section{Discussion}

The results presented here indicate that there are socio-economic and demographic variations in the perception of the campaign. People with a lower education level are also less likely to have seen the campaign. When they have seen the campaign, they are more likely to be receptive to TV spots than higher educational groups. There is also a difference between age groups. We see that young people have seen the campaign more often than older age groups, although they find the campaign less attractive.

Globally, $19 \%$ of the interviewed population does recollect the campaign and, among them, $20 \%$ were able to name correctly its organizing institution. A similar campaign conducted in the USA with a comparable methodology showed that $12.4 \%$ of the respondents was able to recall the radio spot without assistance (1).

There are some possible limitations in the interpretation of the results presented here. We observed a decrease in the number of people who remembered the campaign as we proceeded in time with the telephone survey. The proportion dropped from $25.0 \%$ after one week to $18.8 \%$ after three weeks of surveying and kept going down in the weeks thereafter. This is probably due to a recall bias. Seeing this evolution in a short period of time, we can assume an even lower recall in a longer period of time. Thus, no long-term effect of the campaign on public awareness could probably be attained. As Slater states, it is - among others - repetition that increases the power of the message (4). 
Another limitation was that we had to face the difficulty to reach adolescents by phone: phone numbers lists are only available for fixed lines, leading to an overrepresentation of middle-aged adults and seniors. Young people more often use mobile phones only.

Raising awareness and knowledge about addictive products is evidently necessary, but competing messages in the immediate environment can jeopardize the efficacy of such campaigns (5). Many advertising campaigns use precisely the same type of strategy to induce indistinctness and to increase their brand awareness (4).

The results of our survey indicate that the campaign was globally positively appreciated by the people interviewed, with a global mean appreciation score of 6.62 .

However, in health promotion, reaching lower socio-economic groups still remains a real challenge. The higher the socio-economic background, the lower the risk of being insufficiently informed. Göransson et al. measured the attitude and perception towards and knowledge of health campaigns (6). The authors found no differences in the awareness of the campaign - even though they could suspect a lower awareness in low socio-economic groups, but on the other hand, they found a difference in the knowledge about the health project of the campaign. Contrary to this, Vallone et al. found important socio-economic differences in the awareness about a campaign aimed to prevent youth from smoking (7).

The purpose of our survey was not principally to evaluate the effect of the campaign - even though some questions were addressed on the discussion and reflection that could possibly follow the reception of the messages. The evaluation survey aimed to assess first the campaign impact on the general population rather than the effectiveness of such an initiative. A large coverage can stimulate communication, discussion with peers, family and friends as quoted by Slater (4).

One of the main goals of the campaign was to reach young people, and the results presented above indicate that this objective was accomplished. This age group deserves to be the focus of such campaigns, as for alcohol or other substances, the sooner the initiation, the higher the risk of excessive consumption of those products later on (8). Furthermore, in order to break into new markets, adolescents and young adults represent a very interesting commercial target for the alcohol industry (9). The young population is an easy marketing target and as such is overwhelmed by contradictory or ambivalent messages emanating from food, tobacco and alcohol industries (10). As young people are simultaneously also targeted by health promotion campaigns, this can result in a difficult opinion or decision-making. This constitutes also a challenge for health promotion campaigns and strategies to avoid ambiguity with commercial marketing. As paradoxical as it may seem, in their review of social marketing effectiveness, Stead and al. have shown that "the more similarities they ...[social marketing campaigns] ...had with commercial marketing, the more successful they were (11).

Our results also point out that two types of improvement could be considered for future health campaigns. The first one is related to the choice of the media in order to improve the 
visibility of such a campaign, and the visibility of the organizing institute. To reach young people, the choice of the media is decisive. Maybe more than newspapers, radio spots, SMS and e-mails could be privileged, like it was done in a similar campaign conducted in France (12).

The second possible improvement concerns the structure of the message, designed to reach different social backgrounds equally. Our results have shown that the campaign was mainly seen in the highest socio-economic group, measured by educational level. This is not very surprising, knowing the fact that the message was simply a sentence, with no visual aids, like an image or a picture that could be more eye-catching and attract people who are less familiar with written messages. If well-prepared and adapted to different socio-economic origins, radio and TV spots could overcome this difficulty. The strategy followed by this campaign was a one-shot through many different media channels, resulting in a higher probability to be exposed to the campaign. But to gain long-term effectiveness and greater dissemination, the messages need to be repeated more often (13). This strategy is supported by several marketing campaigns (14).

Assuming that individual behaviors can be changed, direct campaigns, i.e. campaigns addressed directly to the public and not aiming to change the political or economic context, such as the one which is described in this paper, represent an important component in health promotion (15). Voluntary risk-taking could be considered as one of the multiple characteristics of adolescence (16). Therefore, strategies based on "social norms marketing" are very important but may not always be sufficient to prevent misuse in alcohol or other drugs consumption, especially in the targeted public of adolescents and young adults. In this perspective, other environmental dimensions, like peer pressure, family, culture or work related environment could also be considered in a comprehensive strategy.

\section{References}

1. Surkan PJ, Dejong W, Herr-Zaya KM, Rodriguez-Howard M, Fay K. A paid radio advertising campaign to promote parent-child communication about alcohol. J Health Commun 2003, 8, 489-95

2. Perkins J, Sanson-Fisher R. An examination of self- and telephone-administered modes of administration for the Australian SF-36. J Clin Epidemiol 1998, 51, 969-73

3. Beebe T, McRae J, Harrison P, Davern M, Quinlan K. Mail surveys resulted in more reports of substance use than telephone surveys. J Clin Epidemiol 2005, 58, 421-4

4. Slater M. Integrating Application of Media Effects, Persuasion, and Behavior Change Theories to Communication Campaigns: A Stages-of-Change Framework. Health Communication 1999, 11, 335-54

5. Anderson P, Chisholm D, Fuhr DC. Effectiveness and cost-effectiveness of policies and programmes to reduce the harm caused by alcohol. Lancet 2009, 373, 2234-46

6. Görannsson M, Hanson B, Lindbladh E, Stergren P. Using socio-economic differences in knowledge and attitudes to shape community alcohol programmes: experiences from the Kirseberg Project. Health Promotion International 1996, 11, 95-103

7. Vallone $\mathrm{D}$, Allen $\mathrm{J}$, Xiao $\mathrm{H}$. Is socioeconomic status associated with awareness of and receptivity to the truth® Campaign? Drug and Alcohol Dependence 2009, 104, S115-20

8. De Bock C. Alcool et autres drogues, le vrai et le faux. Education Santé 2008 
9. Alcool, cannabis, tabac et autres drogues, Campagne de communication jeunes. Dossier de presse, 2002 [Unpublished Work]

10. Brown J, Witherspoon EM. The mass media and American adolescents' health. Journal of Adolescent Health 2002, 31, 153-70

11. Stead R, Ross G, Angus K, McDermott L. A systematic review of social marketing effectivenes. Health Education 2007, 107, 126-91

12. Mission Ministérielle de lutte contre la drogue et la toxicomanie. Alcool, cannabis, tabac et autres drogues, Campagne de communication jeunes, dossier de presse France, 2002

13. Hafstad A, Aaro LE, Engeland A, Andersen A, Langmark F, Stray-Pedersen B. Provocative appeals in anti-smoking mass media campaigns targeting adolescents--the accumulated effect of multiple exposures. Health Education Research 1997, 12, 227-36

14. Kelly K, Swaim R, Wayman J. The Impact of a Localized Antidrug Media Campaign on Targeted Variables Associated with Adolescent Drug Use. Journal of Public Policy \& Marketing 1996, 15, 238-51

15. Snyder L. Health Communication Campaigns and Their Impact on Behavior. J Nutr Educ Behav 2007, 39 , S32-40

16. Yanovitzky I, Stryker J. Mass Media, Social Norms, and Health Promotion Efforts: A Longitudinal Study of Media Effects on Youth Binge Drinking. Communication Research 2001, 28, 208-39 